\title{
Clinical Evaluation of Pearl Millet Conophor Weaning Mix as Supplementary Food for Nigerian Children
}

\author{
I. A. Akeredolu, A. A. Addo and O. A. Akeredolu* \\ Department of Physical and Health Education Lagos State University, Lagos
}

\begin{abstract}
The purpose of this study was to formulate a weaning diet from pearl millet-conophor nut flour that would promote growth. For PER, BV, NPU and TD values, casein diet was the most superior while millet-conophor diet and soyogi diet compared favourably with each other. For the clinical measurements of the experimental rats on the soy ogi diet and millet-conophor diet, apart from the urinary urea level of the group on millet conophor diet which was much higher than soy-ogi, there was no difference in any of the other parameters measured. It was therefore, concluded that the millet-conophor, diet was favourably well with the soy-ogi.
\end{abstract}

Key words: Clinical Evaluation, Conophor, Weaning Mix, Millet and Supplementary Food

\section{INTRODUCTION}

A look at the traditional weaning diet of babies in our communities reveals that the diets are mainly carbohydrate foods e.g. "Akamu" or "Ogi",(gruel made from fermented maize grains) mashed yam mixed with salt and palm oil and recently the use of soy-ogi [a gruel made of maize pap and soy bean milk]. During the weaning process, children are particularly vulnerable to malnutrition. The weaning period is a very critical period in promoting child nutrition and survival. The period would have been less problematic if only mothers know how to feed their children with locally available foods from sorghum, maize, millet, cowpeas, peanuts and conophor.

Oyenuga [1968] observed that the vast majority of Nigerians are not only improperly fed but are also underfed and the widespread use of wild fruits and nuts to supplement the traditional diet helped to alleviate this problem. According to Adesioye [1991], tree nuts have been used for food since antiquity, although the potentials of most tree nuts have not been fully exploited. The situation is not different for conophor nuts [Tetracarpidium conophorum], although there is no yield record of its annual production.

Many studies have been carried out on the formulation of weaning foods (Guiro et al 1987, Almeida-Dominguez et. al. 1993, Ezeji and Ojimelukwe 1993). Although a lot of the work has been carried out on the formulation of weaning foods from mixtures of legumes and cereals, no work has been carried out on the formulation of weaning food from mixtures of pearl millet and conophor nut. Pearl millet originated in western tropical Africa and has a high protein content as compared with other small grains grown under similar conditions [from 8 to 16\%] and like the other cereal grains, it is deficient in lysine, tryptophan, threonine and sulphur-containing amino acids, although certain species are high in lysine and tryptophan compared to other cereals [FAO, 1991].

\footnotetext{
*Author for correspondence
} 
The purpose of this study, therefore, was to formulate weaning food from mixtures of pearl millet and conophor nut that could be nutritionally acceptable after clinical evaluation.

\section{MATERIALS AND METHODS}

The proximate analysis of conophor nut, pearl, millet, pearl millet-conophor mix and soy-ogi mix were carried out using standard AOAC [1980] procedure. The proximate composition values of yellow maize and soybean were obtained from Oyenuga [1968]. Thin layer chromatography [TLC] was used to analyze the essential amino acid present in the test diet [T3].

The diets were formulated on the basis of their proximate analysis with all the diets containing $10 \%$ protein.

Table 1 - Proximate composition of food samples and diets [\%]

\begin{tabular}{ccccc}
\hline Composition & $\begin{array}{c}\text { Defatted Conophor } \\
\text { Nut }\end{array}$ & Pearl Millet & $\begin{array}{c}\text { Millet-conophor } \\
\text { Mix }\end{array}$ & Soy-ogi \\
\hline Moisture \% & 4.16 & 10.34 & 11.96 & 10.93 \\
Crude Protein \% & 47.25 & 9.63 & 9.56 & 9.71 \\
Ether Extract \% & 1.38 & 3.13 & 1.29 & 3.56 \\
ASH \% & 3.01 & 0.66 & 2.04 & 2.12 \\
Crude fiber \% & 4.68 & 2.84 & 71.27 & 7.84 \\
Nitrogen free & 39.52 & 73.40 & & 71.84 \\
extractives \% & & & & \\
\hline
\end{tabular}

Four diets were evaluated for protein quality, which involved the use of 20 female weaning albino rats. Five littermates rats obtained from the Animal house of College of Medicine, University of Lagos [CMUL] were allocated to each diet using randomized block design. The rats were between 22-24 days old with an average initial weight of $29.25 \mathrm{~g}$.

The rats were weighed to the nearest $0.1 \mathrm{~g}$ at the start of the trial and allocated on the basis of weight, into groups of five rats each, with blocks representing variations in initial weight. The rats in each block were randomized for diet and cage. The animals were housed in individual galvanized wire cages. The animals were subjected to five days adaptation to the laboratory on $10 \%$ casein diet and later divided into four groups of five rat each with inter-group difference of $1.0 \mathrm{~g}$ and $5 \mathrm{~g}$. One group designated as control group was placed on $10 \%$ casein diet [T1], another group was placed on soy-ogi diet [T2], a third group was placed on pearl millet-conophor flour diet [T3] and another group was placed on a protein-free diet [T4]. All the rats were given weighed pellets of the appropriate test diet, which minimized the scattering of food and permitted accurate recording of feed consumed. A daily weighing of feed consumption and remains was made. A weekly record of feed intake and body weight was maintained. The faeces were collected at intervals. Each day's collection was stored in the refrigerator. At the end of the collection period, the bulk faeces for each rat was dried, weighed and then ground into powder. The collection of the urine was done every other day and stored in small bottles and kept in the freezer.

Nitrogen content of the faeces and urine was determined by the standard macro. Kjeldal method. [A.O.A.C, 1980]. On the $28^{\text {th }}$ day, the rats were killed, and blood samples were collected into heparin bottles and analyzed for urea, creatine and glucose. Urine samples were also analysed for urea and creatine.

\section{RESULTS AND DISCUSSION}

Analysis of variance was used in analyzing the data, which was followed by the use of Duncan's multiple range tests to show the difference between means at 0.05 level of significance.

Fig. 1 presents the weekly live weight gains of the experimental animals. 


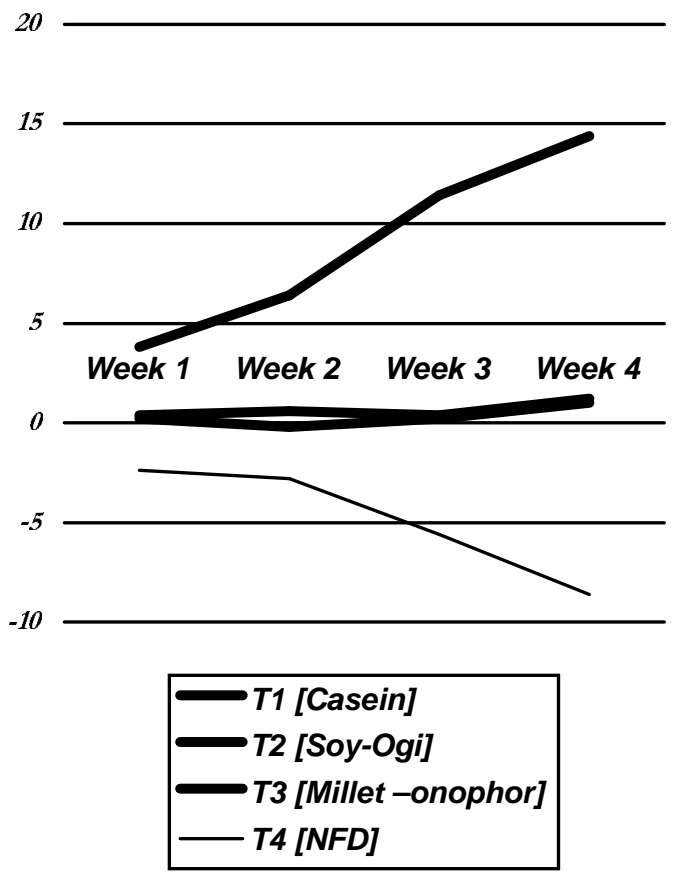

Figure 1

Table 2 - Average weekly live weight gains of experimental rats [5 rats per group]

\begin{tabular}{cccccc}
\hline Diet & Week 1 & Week 2 & Week 3 & Week 4 & Grand Mean \\
\hline T1 [Casein] & 3.8 & 6.4 & 11.4 & 14.4 & $9.0^{\mathrm{a}}$ \\
T2 [Soy-Ogi] & 0.4 & 0.6 & 0.4 & 1.2 & $.065^{\mathrm{b}}$ \\
T3 [Millet - & 0.2 & -0.2 & 0.2 & 1.0 & $0.30^{\mathrm{b}}$ \\
conophor] & & & & -8.6 & $-4.85^{\mathrm{c}}$ \\
T4 [NFD] & -2.4 & -2.8 & -5.6 & -8.6 \\
\hline
\end{tabular}

a,b,c Means in the same column with different superscripts are significantly different.

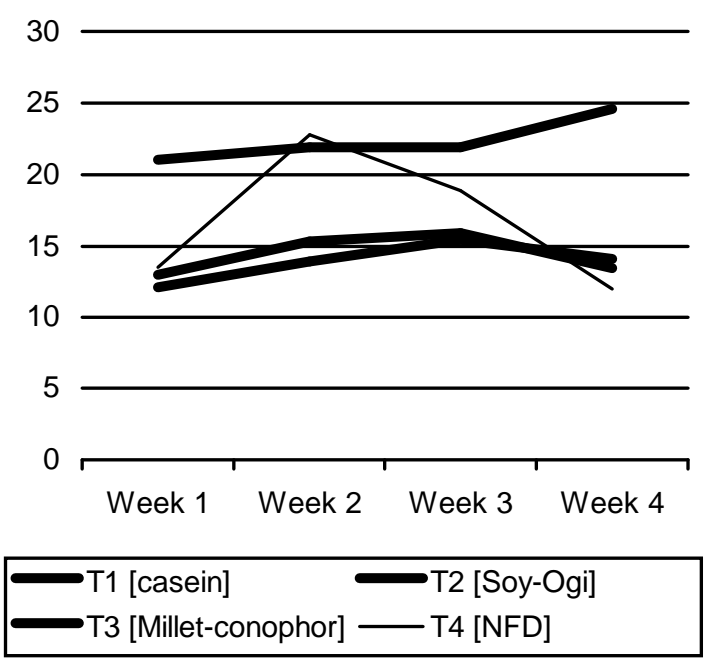

Figure 2 
The animals on diet $\mathrm{T} 1$ increased steadily in weight from week 1 through week 4 , whereas the animals on diet $\mathrm{T} 2$ gained $[0.2 \mathrm{~g}]$ at week 1 , increased slightly at week $2[0.6 \mathrm{~g}]$ then fell back to $0.4 \mathrm{~g}$ at week 3 , and increased at week 4.1 $[1.2 \mathrm{~g}]$. For the animals on diet T3, however, there was a weight gain at week $1[0.2 \mathrm{~g}]$ with a slight gain in week 3 [0.2] which increased to $1.0 \mathrm{~g}$ in week 4 . There was consistent loss in weight by the animals on diet T4 from week 1 through week 4.

As shown in Table 2, analysis of variance revealed differences in the grand mean weight gain of the experimental rats. Duncan's multiple ranges test showed that differences existed between the animals on casein diet [T1], soy-ogi [T2] and millet-conophor diet respectively. There was no significant difference between the grand mean live weight gains of the animal on soy-ogi diet and millet-conophor diet.

Fig. 2 present the feed intake per week of the experimental rats.

As shown in Fig. 2, the animals in diet T1 had a marked increase in feed intake from week 1 through 4, although, there was a slight decrease in week 2. For the animals on diet $\mathrm{T} 2$ and $\mathrm{T} 3$, the average feed intake increased between weeks 1 and 3; but there was a decline in week 4 . The animals on diet $\mathrm{T} 4$ increased their feed intake in week 2 , thereafter a decrease occurred in weeks 3 and 4.

Table 3 presents the average weekly feed intake of rats on the experimental diets.

Table 3 - Average weekly feed intake of rats on the experimental diets

\begin{tabular}{cccccc}
\hline Diet & Week 1 & Week 2 & Week 3 & Week 4 & Grand mean \\
\hline T1 [casein] & 21.04 & 21.92 & 21.90 & 24.60 & $22.37 \mathrm{a}$ \\
T2 [Soy-Ogi] & 13.00 & 15.34 & 15.92 & 13.48 & $11.44 \mathrm{~b}$ \\
T3 [Millet- & 12.14 & 13.90 & 15.42 & 14.08 & $13.89 \mathrm{~b}$ \\
conophor] & & & & & \\
T4 [NFD] & 13.52 & 22.76 & 18.86 & 12.02 & $16.79 \mathrm{~b}$ \\
\hline
\end{tabular}

$a, b$, means in the same column with different superscripts are significantly different.

Table 4 - Biochemical measurement of protein utilization by rats on the experimental diets

\begin{tabular}{ccccc}
\hline Indices & T1 [Casein] & T2 [Soy-Ogi] & $\begin{array}{c}\text { T3 [Millet- } \\
\text { conophor] }\end{array}$ & T4 [NFD] \\
\hline Urinary N [mg/ml] & 3.94 & 4.30 & 4.30 & 3.84 \\
Urinary urea & 17.72 & 32.98 & 52.52 & 34.96 \\
$\quad[\mathrm{mg} / \mathrm{dl}]$ & & 15.00 & & \\
Blood urea [mg/dl] & 12.00 & 0.50 & 19.00 & 26.00 \\
Blood creatinine & 0.30 & & 0.50 & 0.70 \\
$\quad[\mathrm{mg} / \mathrm{dl}]$ & & 16.0 & 16.00 & 11.00 \\
Glucose [mg/dl] & 11.00 & 0.61 & 0.62 & 0.47 \\
Faecal N [g/100g] & 0.59 & & & \\
\hline
\end{tabular}

Across the treatment, analysis of variance showed that there were difference in the mean feed intake of the test animals. Duncan's multiple range test revealed that the differences existed between the mean feed intake of the animals on the casein diet and the animals on all the other diets, whereas, no significant difference existed between the animal on diet $\mathrm{T} 2$ and $\mathrm{T} 3$, diets $\mathrm{T} 2$ and $\mathrm{T} 4$, and diets $\mathrm{T} 3$ and T4. Table 4 presents the clinical performance of the experimental rats
As shown in Table 4, diets T2 and T3 indicated a similarity in nitrogen excretion of the animals. The creatinine levels of all the groups fell within similar levels with the exception of the animals on the nitrogen free diet [NFD], which had the highest creatinine levels. The urinary urea level of the animals on the casein diet had the lowest values while those on diets $\mathrm{T} 2$ and $\mathrm{T} 4$ had similar values. The values for the animals on diet T3 were quite high comparatively. 
Glucose levels of the animals on diets $\mathrm{T} 1$ and $\mathrm{T} 4$ were alike and the same similarity exists for those on diets $\mathrm{T} 2$ and $\mathrm{T} 3$.

\section{Feed Intake and Live Weight Gain of Experimental Rats}

Table 1 and 2 show the results of the live weight gains and feed intake of the experimental animal evidently the animals on the casein diet [T1] had a steady increase in their feed intake with a corresponding increase in their weight gain; this was expected because growth rate in rats was influenced by their feed intake. For the animals on diets T2 and T3, there was an increase in feed intake between week 1 and week 3 which did not correspond to the weight gain in both groups. For diet $\mathrm{T} 2$, the animals had a higher weight gain in week 2 than in week 3 although the feed intake in week 3 was higher than that of week 2 . For the animals on diet $\mathrm{T} 3$, despite the increase in feed intake in week 2 , there was a loss in weight; this could be as a result of some inexplicable factors. In week 3 , the increase in feed led to only a small increase in weight.

An interesting observation in the animals on diets $\mathrm{T} 2$ and T3 was that in week 4, animals in both groups had a decline in their feed intake and yet there was an increase in weight that surpassed that of the previous weeks. It could be that the experiment came to an end, just when the animals on both groups were getting used to the diets, or the weight gain could be as a result of causes other than that of feed intake. Eggum [1989] had reported that live weight gain may not be related to protein stored.

For the animals on the NFD, there was an increase in the feed intake in the $2^{\text {nd }}$ week [although, it gave rise to a loss in weight]. The depression in the intake in the $3^{\text {rd }}$ and $4^{\text {th }}$ week consequently led to further losses in weight. The initially high consumption of feed by the animals on the NFD was probably to make up for the absence of protein in the diet, but as the animals began to loose weight, the consumption of feed reduced probably to match the loss in weight. It has been suggested that feed intake of animals depend on the protein content and the amino acid balance of the diet. From the above findings, the hypothesis that there would be no significant difference in the live weight gain and feed intake of experimental rats fed millet-conophor mix and other mixes was rejected.

\section{Nitrogen utilization and Excretion}

As indicated in Table 3 the nitrogen excretion of the animals on diets T2 and T3 were similar. This could suggest that the essential amino acid content of these proteins were equally utilized. The creatinine levels of all the groups fell within similar levels with the exception of the animals on the NFD which had the highest creatinine levels as expected because in a nitrogen free diet, the animal continued to loose nitrogen and eventually, the creatinine of the muscle was converted to creatinine, which was excreted in the urine. This result was in agreement with that of Makinde et al [1982] who made similar observations in their study on protein quality of infant's formulas.

The urinary urea level of the casein diet had the lowest value as expected. The values for the animals on the soy-ogi diet and NFD diets were similar whereas that of the group on milletconophor diet were quite high comparatively. It is known that the greater part of the nitrogen in the urine of animals on NFD is in the form of urea and so the urea levels of the animals on the diet T4 [NFD] is not surprising, but the reason for the urea level of the animals on the millet conophor mix could be that of the presence of other antinutritional factors other than phytic acid [e.g. polyhenols and saponins] which normally decrease nitrogen absorption and retention. Tamir and Alimot [1970] reported that anti-nutritional factors reduced nitrogen absorption and retention, thereby increasing faecal and urinary nitrogen excretion.

There was an inverse relationship between the blood urea level of the millet-conophor diet [ $r=0.7]$ and the biological value [BV]. This implied that the higher the biological value, the lower was the blood urea levels. This could be supported by the findings of Munchow and Bergner [1968], Eggum [1970] and Makinde et al [1982] who observed a significant relationship between the BV of a diet and the blood urea content. The glucose levels of the animals in diets $\mathrm{T} 1$ and $\mathrm{T} 4$ were similar and the same similarity existed for diets $\mathrm{T} 2$ and $\mathrm{T} 3$.

\section{CONCLUSION}

For clinical measurements of the experimental rats on the soy-ogi diet and millet-conophor diet, it was observed that apart from the urinary urea level of the group on millet conophor diet which was much higher than so-ogi, there was no difference 
in any of the other parameters measured. It could therefore, be concluded that the millet-conophor diet was acceptable and found to compare favourably well with the soy-ogi diet although they both did not promote growth at $10 \%$ protein level.

\section{ACKNOWLEDGEMENT}

We acknowledge the following member of Federal Institute of Industrial Research, Oshodi [FIRO], Lagos, Dr. S.O. Onabowale [Food Toxicology], Mr. John Mohammed [Food Laboratory] and Mr. Sam. Olatope [Bio technology]. Our sincere thanks to Mr. Uche Arukwe [Dept of Biochemistry (CMUL) and Mr. Lawson [Clinical Pathology (LUTH)] for biochemical analysis.

\section{REFERENCES}

Adesioye, H. O. (1991), The effect of processing and storage on the chemical and sensory quality of conophor nut. Nigerian food journal, 9, 33-38

Almedia-Dominguez, H. D.; Serna-Saldivar, S. O.; Gomez, M. H.and Rooney, L. W. (1993), Production and Nutritional Value of weaning food from mixtures of pearl millet and cowpeas. Cereal chemistry, 70 : (1), 14-18.

AOAC (1980), Association of official Analytical chemists official methods of analysis, Washington D.C.

Ezeji, C. and Ojimelukwe, P. C. (1993), Effect of fermentation on the nutritional quality and functional properties of infant food formulations prepared form Bambara-Groundnut, fluted-pumpkin and millet seed. Plant-foods for Human Nutrition, 44 : (2), 267-276.

Food and Agriculture Organization. (1991), Agricultural services Bulletin Post Harvest and Processing Technologies of African staple Foods: a Technical Compendium. F.A.O. of the United Nations, Rome, 89, 41-54.

Guiro, A. T.; Kane, O. and N'Diaye, A. M. (1987), Protein calorie malnutrition in Senegalese children. Effect of Rehabilitation with a pearl millet weaning food. Nutritional Report International, 36 : (5), 1071-1097.
Eggum, B. O. (1970), Blood urea measurement as a technique for assessing protein quality. British Journal of Nutrition, 24, 983-988.

Eggum, B. O. (1989), Biochemical and methodological Principles. In: Rock, H. D.; Eggum, B. O.; Low, A. G.; Simon, O. and Zebrowska, T. (Eds.). Protein Metabolism in Farm Animals, Oxford Science Publications. Berlin.

Makinde, M. A.; Osinubi, O. A.; Akpoterabor, C. E.; Elemo, B. and Lachance, P. A. (1982), Protein quality evaluation of locally processed and some imported infant weaning formulas. Nigerian journal of nutritional science.

Munchow, H. and Bergner, H. (1967), Examination of techniques for protein evaluation of feedstuffs. Archiv. Fur Tierenahrung, 17, 141-150.

Oyenuga, V. A. C. (1968), Nigeria's Food and Feeding Stuffs: their chemistry and Nutritive value. University Press, Ibadan.

Tamir, M. and Alimot, E. (1970), Carob-tennis growth depression levels of insoluble nitrogen in the digestive tract of rats. Journals of nutrition, 100, 573-580.
Received: November 07, 2002; Revised: September 02, 2003 . Accepted: April 04, 2005. 